\title{
Emergency endoscopic variceal ligation following variceal rupture in patients with advanced hepatocellular carcinoma and portal vein tumor thrombosis: a retrospective study
}

Toshihiro Kawai ${ }^{1,2^{*}}$, Yoko Yashima ${ }^{2}$, Takafumi Sugimoto ${ }^{2}$, Takahisa Sato ${ }^{2}$, Miho Kanda ${ }^{2}$, Nobuyuki Enomoto ${ }^{1}$, Shinpei Sato ${ }^{2}$ and Shuntaro $\mathrm{Obi}^{2}$

\begin{abstract}
Background: The outcomes of treatment of ruptured varices in patients with hepatocellular carcinoma (HCC) and portal vein tumor thrombus (PVTT) are unclear. We therefore evaluated the long- (rebleeding and death) and shortterm (immediate death within $24 \mathrm{~h}$ of variceal bleeding diagnosis) outcomes of patients with PVIT who underwent emergency variceal band ligation.

Methods: Data on 62 patients with PVTT and endoscopically proven esophageal or gastric variceal bleeding from 2007 to 2012 were studied. In most cases, the varices were treated using endoscopic variceal band ligation (EVL). We assessed the patients' rebleeding-free and overall survival using the Kaplan-Meier method, and a Cox proportional hazard model was used to analyze effect of independent factors on rebleeding-free and overall survival times.

Results: Most patients had decompensated cirrhosis and were classified as Child-Pugh class B (56\%) or C (36 \%). A total of 35 patients (56\%) had PVIT in the main portal trunk. Among all patients, 58 (94\%) and 4 (6\%) had esophageal and gastric variceal bleeding, respectively. Bleeding was managed using EVL in all, but one patient (98\%) who was treated with a Sengstaken-Blakemore tube. A total of 24 patients (39.3\%) experienced rebleeding, and these patients had a median overall survival time of 36 days. A PVTT in the main portal trunk was predictive of rebleeding (hazard ratio 3.706, $p=.0223$ ), and a-fetoprotein-L3 levels $<37.4 \%$ (hazard ratio $0.464, p=0.015$ ) and Child-Pugh class A/B (hazard ratio $0.398, p=0.007$ ) were associated with overall survival. We observed 95 bleeding events in 62 patients. EVL achieved hemostasis in 92 of the 95 bleeding events, whereas seven immediate deaths occurred due to variceal bleeding (7/92, 7.6\%). All three bleeding events treated with modalities other than EVL resulted in immediate deaths.

Conclusions: EVL is a safe and effective treatment of variceal ruptures in patients with HCC and PVTT. After successful hemostasis, alleviation of the underlying liver function impairment and tumor control are equally important for a good prognosis.
\end{abstract}

Keywords: Esophageal varices, Endoscopic variceal ligation, Hepatocellular carcinoma, Portal vein tumor thrombus

\footnotetext{
* Correspondence: toshihirokawai51@gmail.com

${ }^{1}$ First Department of Internal Medicine, Faculty of Medicine, University of

Yamanashi, 1110 Shimokawato, Chuo, Yamanashi 409-3898, Japan

${ }^{2}$ Gastroenterology and Hepatology, Kyoundo Hospital, Sasaki Institute, Tokyo,

Japan
} 


\section{Background}

Hepatocellular carcinoma (HCC) is the sixth most common cancer worldwide [1]. Due to the condition's very poor prognosis, the number of deaths due to $\mathrm{HCC}$ is similar to its incidence, making it the third most common cause of cancer-related deaths [1]. The majority of HCC cases develop as part of the natural course of liver cirrhosis [2]. Despite the recommended surveillance, $\mathrm{HCC}$ is often only detected at an advanced stage [3, 4], particularly in patients with a portal vein tumor thrombus (PVTT; $12.5-39.7 \%$ of cases) [4-8]. Although an increasing variety of therapeutic options that offer survival benefits are available for patients with HCC [9], the long-term prognosis of HCC remains poor because HCC recurrence and PVTT development remain uncontrollable [10].

A PVTT significantly affects the prognosis of HCC patients because it often leads to the extensive spread of the tumor throughout the liver and increases portal blood pressure, resulting in variceal ruptures, ascites, hepatic encephalopathy, liver failure, and death [11]. There has been a substantial improvement in the survival of patients with variceal bleeding owing to the use of vasoactive drugs [12], the introduction of endoscopic variceal band ligation (EVL) [13-15] and endoscopic injection sclerotherapy (EIS) $[16,17]$. Several studies have examined the prognoses associated with variceal bleeding, but most have been observational studies that have excluded patients with HCC [18-23]. Therefore, the long-term outcomes of ruptured variceal treatment in patients with advanced HCC and PVTT remain unclear.

This study evaluated the long- (rebleeding and death) and short-term (immediate death) outcomes of HCC patients with ruptured esophageal or gastric varices and a PVTT.

\section{Methods}

\section{Study design, setting, and data collection}

We conducted a retrospective study using data from a database that included all patients admitted to the Kyoundo Hospital (Tokyo, Japan) for HCC between January 2007 and December 2012. The database was part of a project to evaluate the effect of current therapies on the prognosis of PVTT-related variceal bleeding and was approved by the Institutional Review Board of the Kyoundo Hospital. All data were collected in the context of standard practice from patient clinical records, anonymized, and populated into a protected database.

Diagnosis of hepatocellular carcinoma, portal vein tumor thrombi, and variceal bleeding

HCC was diagnosed based on standard computed tomography (CT) findings [24]. A PVTT was defined as the presence of HCC invading the main trunk or the first or second branches of the portal vein on CT findings. Gastric varices were classified based on the following criteria [25]: Gastroesophageal varices (GOVs) were associated with varices along the lesser curvature of the stomach (type 1 [GOV1]) or along the fundus (type 2 [GOV2]). Isolated gastric varices (IGVs) were present in isolation in the fundus, at ectopic sites in the stomach (IGV1), or at the first part of the duodenum (IGV2). The status of each patient was assessed at the time of admission.

All patients were diagnosed as having bleeding esophageal or gastric varices by emergency endoscopy within $24 \mathrm{~h}$ of the hemorrhage. Acute variceal bleeding was diagnosed when blood was observed to emanate from a varix, or when fresh blood was seen in the esophagus of patients with varices displaying the white nipple sign [26] and in whom no other potential site of bleeding was identified. Standard therapy for variceal bleeding included blood transfusions, fluid and electrolyte replacement, and lactulose administration, as necessary.

\section{Endoscopic variceal band ligation}

Following the emergency endoscopy to identify the bleeding points, a flexible overtube (Sumitomo Bakelite, Tokyo, Japan) was inserted, and the esophageal varices were ligated using a pneumatic EVL device (Sumitomo Bakelite). Ligation was initially applied at the bleeding point and performed with 1-3 rubber bands. After the ligation was completed, the ligation sites were sprayed with water and suctioned to check for persisting bleeding. Rescue therapies (e.g., a Sengstaken-Blakemore balloon tamponade [27]) were applied when necessary. Initial success was defined as bleeding cessation and vital sign stabilization.

\section{Follow-up of patients}

Follow-up of the enrolled patients was continued until December 2013. Data regarding patient demographics, liver disease, and bleeding episodes were registered in the database.

\section{Variables and statistical analysis}

Recurrent bleeding was defined as hematemesis recurring after initial EVL treatment. Immediate death was defined as death within $24 \mathrm{~h}$ of diagnosing the variceal bleeding. Rebleeding-free survival was calculated from the initial date of the therapy to the date of rebleeding or death and assessed by the Kaplan-Meier method. Overall survival was defined as the interval from the initial treatment to death. A Cox proportional hazard model was used to analyze the effects of independent factors on survival. Possible predictors entered into the model included patient characteristics (age and sex), viral characteristics (hepatitis B virus surface antigen and 
hepatitis $\mathrm{C}$ virus antibody levels), the presence of ascites, the presence of encephalopathy, tumor characteristics (maximum tumor dimension, tumor number, portal vein invasion, and extrahepatic metastasis), laboratory test results (albumin, alanine transaminase, aspartate transaminase, and total bilirubin levels; prothrombin time; and platelet count), and serum levels of tumor markers $(\alpha$-fetoprotein $[\mathrm{AFP}]$, AFP-L3, and des-gamma carboxyprothrombin $[\mathrm{DCP}])$, site of variceal rupture, EVL success, and the presence of rebleeding varices. Each continuous variable was transformed into categorical data consisting of two ordinal numbers using the median value for Cox regression analyses, except for AFP and DCP. The cutoff values were set at $100 \mathrm{ng} / \mathrm{mL}$ and $100 \mathrm{mAU} / \mathrm{mL}$ for AFP and DCP, respectively [10]. All statistical analyses were considered significant at $p<0.05$. Statistical analysis was performed with the Stat View 5.0 statistical software (SAS Institute, Cary, NC, USA).

\section{Results}

\section{Patient characteristics}

A total of 2123 HCC patients who were admitted to the Kyoundo Hospital between January 2007 and December 2012 were retrospectively registered in the database. Among these, 472 patients (22.2 \%) had a PVTT and 62 $(62 / 472 ; 13.1 \%)$ were diagnosed with bleeding varices. Thus, the final analysis included 62 patients (Fig. 1).

The median age of the patients was 62 years (range, $30-79$ years), 51 (82\%) were men and 11 (18\%) women
(Table 1). The patients' liver cirrhosis etiologies were hepatitis B $(n=25 ; 40 \%)$, hepatitis C $(n=27 ; 44 \%)$, and non-B non-C hepatitis $(n=10 ; 16 \%)$. The patients were classified based on their liver function as Child-Pugh classes A $(n=5 ; 8 \%)$, B $(n=35 ; 56 \%)$, or C $(n=22$; $36 \%)$. Among all patients, $56 \%$ had a PVTT in the main portal trunk, and $27 \%$ had extrahepatic metastasis. None of the patients had a history of preventive procedures for varices.

\section{Variceal bleeding and occurrence of rebleeding}

Upper gastrointestinal tract endoscopic examination for the bleeding sites revealed that $58(94 \%)$ and $4(6 \%)$ patients had esophageal and gastric variceal bleeding, respectively. All were classified as GOV1. The bleeding was managed using EVL except for one patient who was treated with a Sengstaken-Blakemore tube. Complete initial hemostasis was achieved in all patients.

A total of 24 patients (39.3\%) experienced rebleeding. Although EVL successfully stopped the initial bleeding, 33 rebleeding events occurred in 62 patients $(0-5$ rebleeding events in each patient). A total of 4 and 14 patients experienced rebleeding within 7 and 30 days, respectively (Table 2).

\section{Rebleeding-free and overall survival}

The median rebleeding-free survival time was 29 days (95\% CI, 18-40 days), and the 7-, 30-, 60-day, and 1-

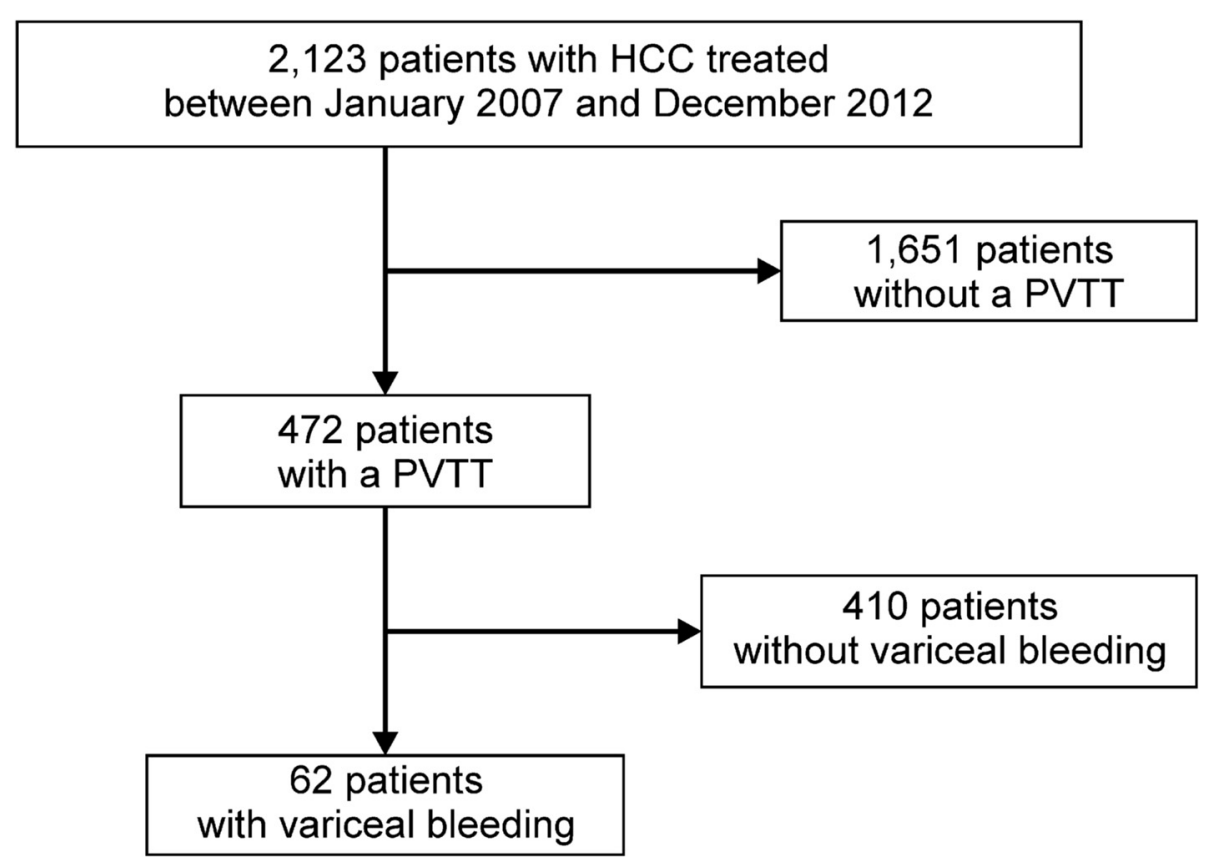

Fig. 1 Flowchart of the study cohort selection. A total of 2123 hepatocellular carcinoma patients who were admitted to the Kyoundo Hospital between January 2007 and December 2012 were retrospectively registered in the database. Among these, 472 patients (22.2 \%) had a portal vein tumor thrombus, and 62 (62/472; $13.1 \%)$ experienced bleeding varices. HCC hepatocellular carcinoma, PVTT portal vein tumor thrombus 
Table 1 Patient baseline characteristics

\begin{tabular}{|c|c|}
\hline Variable & \\
\hline Age (years) & $62(30-79)$ \\
\hline Sex (male/female) & $51 / 11$ \\
\hline Viral infection (HBV/HCV/NBNC) & $25 / 27 / 10$ \\
\hline Ascites (+/-) & $12 / 50$ \\
\hline Encephalopathy (+/-) & $8 / 54$ \\
\hline Albumin (g/dL) & $2.9(1.7-4.1)$ \\
\hline Total bilirubin (mg/dL) & $1.4(0.4-21.4)$ \\
\hline Prothrombin time (\%) & $68(15-120)$ \\
\hline Platelet count $\left(\times 10^{4} / \mathrm{mm}^{3}\right)$ & $12.0(2.6-67.2)$ \\
\hline AST (IU/L) & $117.0(26-2882)$ \\
\hline ALT (IU/L) & $48.5(11-865)$ \\
\hline Child-Pugh class (A/B/C) & $5 / 35 / 22$ \\
\hline Tumor size (cm) & $6.8(1.6-20)$ \\
\hline Tumor number (single/multiple) & $5 / 57$ \\
\hline Extrahepatic metastasis (+/-) & $17 / 45$ \\
\hline PVTT (main trunk/others) & $35 / 27$ \\
\hline $\operatorname{AFP}(n g / d L)$ & $1780.5(2-3535473)$ \\
\hline AFP-L3 (\%) & $37.4(0.5-94.2)$ \\
\hline $\mathrm{DCP}(\mathrm{ng} / \mathrm{dL})$ & $7260(7-402000)$ \\
\hline Variceal rupture (esophagus/stomach) & $58 / 4$ \\
\hline
\end{tabular}

$A F P$ a-fetoprotein, AFP-L3 lectin-reactive a-fetoprotein, $A L T$ aspartate aminotransferase, $A S T$ alanine aminotransferase, $D C P$ des-gamma carboxyprothrombin, $H B V$ hepatitis $B$ virus, $H C V$ hepatitis $C$ virus, NBNC non-B non-C hepatitis, PVTT portal vein tumor thrombus

year rebleeding-free survival rates were 79.0, 50.0, 30.6, and $6.5 \%$, respectively (Fig. 2).

We detected a median overall survival time of 36 days (95 \% CI, 23-63 days; Fig. 4). The 7-, 30-, 60-day, and 1year overall survival rates were 83.9, 59.7, 38.7, and $8.1 \%$, respectively (Fig. 3). Despite achieving initial hemostasis, 10 patients died within 1 week. Only one patient survived for more than 5 years in this study. This patient developed HCC following hepatitis B-related cirrhosis in 2003. In 2007, a PVTT was found in the left branch of the patient's portal vein, and arterial infusion

Table 2 Outcomes of endoscopic variceal band ligation

\begin{tabular}{lll}
\hline Hemostasis rate & $\begin{array}{l}98.4 \% \\
(61 / 62)\end{array}$ & $\begin{array}{l}\text { An SB tube was used } \\
\text { in one patient }\end{array}$ \\
Rebleeding rate & $\begin{array}{l}39.3 \% \\
(24 / 61)\end{array}$ & 4 patients within 7 days \\
& & 14 patients within \\
& 30 days \\
Occurrence of rebleeding & 33 & \\
(frequency) & events \\
$\begin{array}{l}\text { Median rebleeding-free } \\
\text { survival time }\end{array}$ & 29 days \\
MST & 36 days
\end{tabular}

MST median survival time, SB Sengstaken-Blakemore chemotherapy with 5-fluorouracil in combination with interferon was administered [28]. An esophageal varix rupture occurred during chemotherapy, and EVL was performed. After hemostasis, arterial infusion chemotherapy was continued, resulting in tumor shrinkage and PVTT disappearance. The patient did not experience any rebleeding and was still alive in 2015.

\section{Prognostic factors for rebleeding-free survival}

Among the 21 possible predictors we examined, our univariate analysis showed that a PVTT in the main trunk was the only significant factor affecting rebleeding-free survival (hazard ratio 3.706, $p=0.0223$; Table 3). The median rebleeding-free survival time was 24 days in the patient group with a PVTT in the main portal trunk and 34 days in the patient group with a PVTT in the first or second branches of the portal vein $(p=0.6313)$.

\section{Prognostic factors for overall survival}

Sixteen in-hospital deaths occurred among the patients included in this study. Overall survival was affected by Child-Pugh class $(p<0.0001)$, AFP-L3 levels $(p=0.0080)$, and prothrombin time $(p=0.0161)$ in the univariate analysis (Table 4). The multivariate analysis showed that Child-Pugh class A/B (hazard ratio 0.398, $p=0.0065$ ) and AFP-L3 levels <37.4 \% (hazard ratio 0.464, $p=$ 0.0147 ) were independent prognostic factors of overall survival (Table 5). The median overall survival time was 18 days for Child-Pugh class $C$ patients and 64 days for Child-Pugh class A/B patients $(p<0.0001$, Fig. 4).

\section{Immediate death rates}

We observed 95 bleeding events in 62 patients (1-6 events in each patient). EVL achieved hemostasis in 92 of the 95 bleeding events, and seven immediate deaths due to variceal bleeding (7/92; $7.6 \%)$ were recorded. Of the three bleeding events treated with modalities other than EVL, all resulted in immediate deaths, indicating that EVL is useful for preventing immediate deaths after variceal bleeding $(p=0.0009)$.

\section{Discussion}

Up to $40 \%$ of patients with acute bleeding from esophageal varices have been reported to die from exsanguination; in other cases, death is due to bleeding complications, including liver failure, infections, and hepatorenal syndrome $[29,30]$. Our study shows that EVL can produce a high rate of successful hemostasis in patients with variceal ruptures and a PVTT. EVL-treated bleeding events resulted in significantly lower immediate mortality rates than those treated with other modalities, suggesting that EVL is useful for preventing immediate death due to exsanguinating variceal bleeding. 


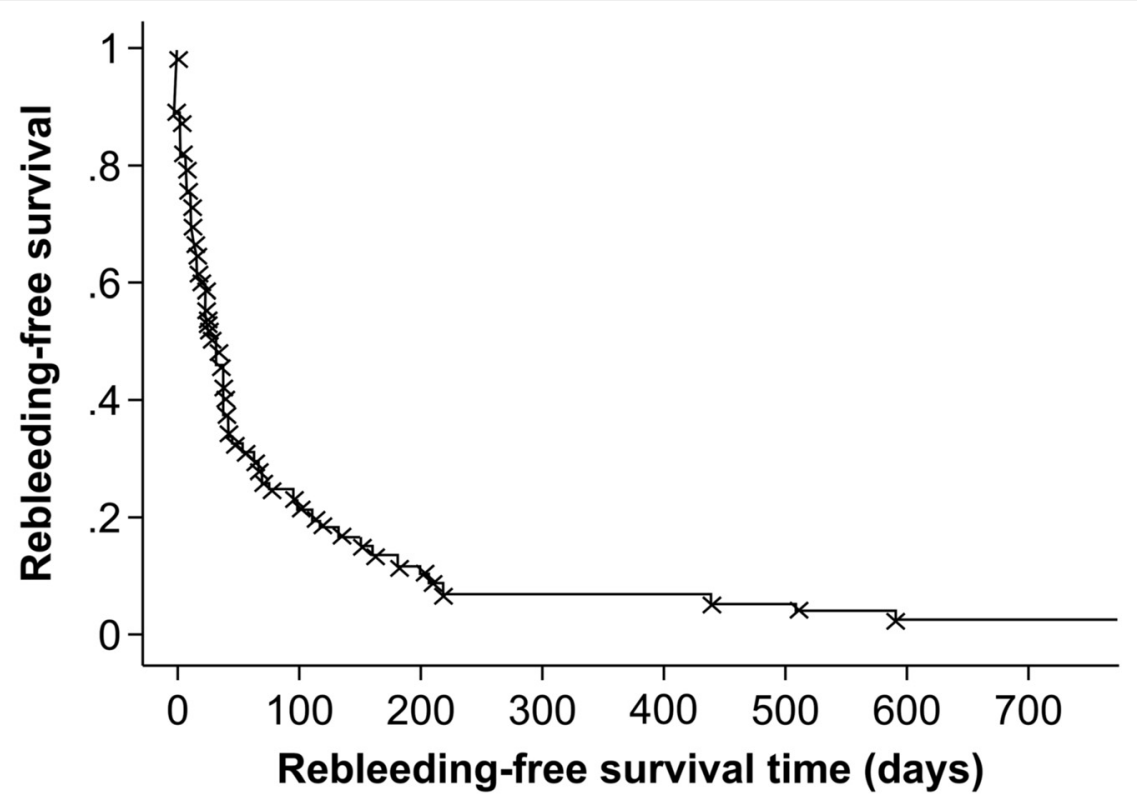

No.at risk 0 day 7 days 30 days 60 days 365 days

$\begin{array}{lllll}62 & 49 & 31 & 19 & 4\end{array}$

Fig. 2 Rebleeding-free survival. The 7-, 30-, 60-day, and 1 year rebleeding-free survival rates were 79.0, 50.0, 30.6, and $6.5 \%$, respectively

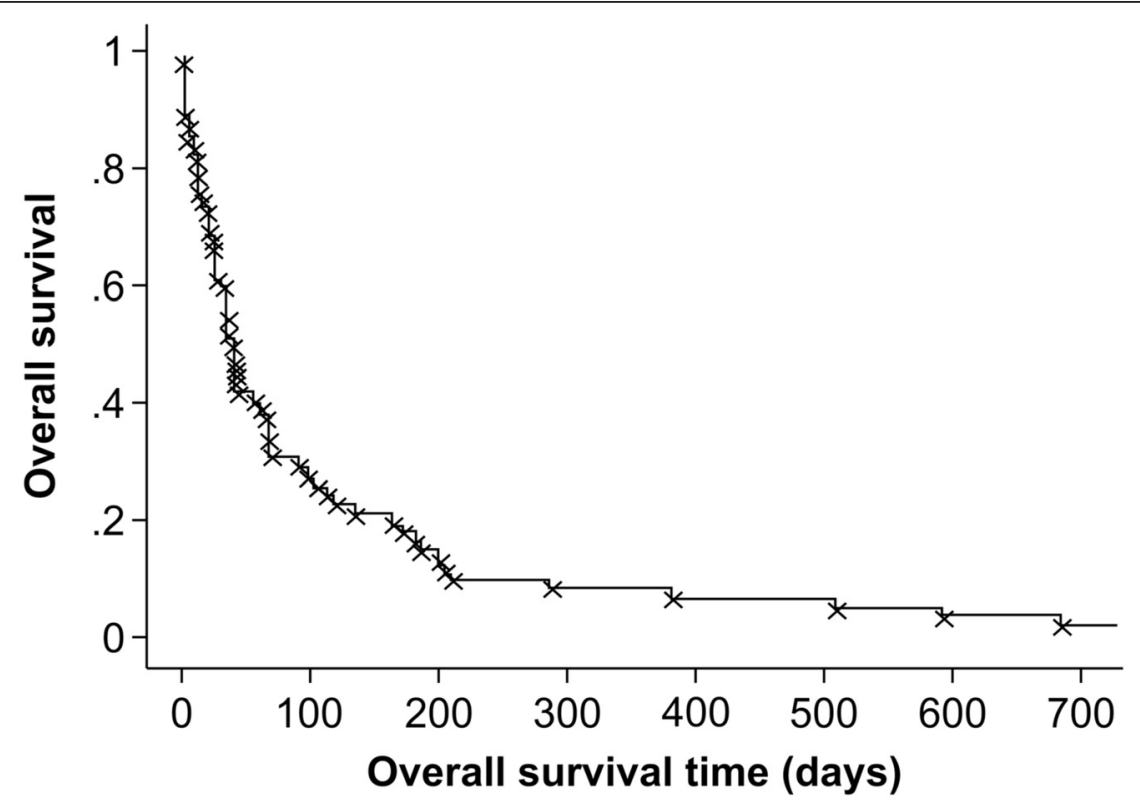

No.at risk 0 day 7 days 30 days 60 days 365 days

$\begin{array}{lllll}62 & 52 & 37 & 24 & 5\end{array}$

Fig. 3 Overall survival. The 7-, 30-, 60-day, and 1-year overall survival rates were 83.9, 59.7, 38.7, and 8.1 \%, respectively 
Table 3 Significant predictors for rebleeding-free survival

\begin{tabular}{|c|c|c|c|}
\hline Variable & Hazard ratio & $95 \% \mathrm{Cl}$ & $p$ value \\
\hline Age $>62$ years & 0.466 & $0.165-1.318$ & 0.1500 \\
\hline Sex (male) & 1.129 & $0.292-4.360$ & 0.8602 \\
\hline $\mathrm{HCV}$ & 1.046 & $0.338-3.238$ & 0.9382 \\
\hline NBNC & 1.778 & $0.403-7.845$ & 0.4474 \\
\hline Ascites (+) & 1.333 & $0.354-5.026$ & 0.6709 \\
\hline Encephalopathy (+) & 1.780 & $0.382-7.559$ & 0.4857 \\
\hline Albumin $>2.9 \mathrm{~g} / \mathrm{dL}$ & 0.714 & $0.255-2.003$ & 0.5224 \\
\hline Total bilirubin $>1.4 \mathrm{mg} / \mathrm{dL}$ & 0.436 & $0.153-1.244$ & 0.1208 \\
\hline Prothrombin time $>68 \%$ & 1.729 & $0.615-4.860$ & 0.2987 \\
\hline Platelet count $>12.0 \times 10^{4} / \mathrm{mm}^{3}$ & 2.147 & $0.759-6.074$ & 0.1500 \\
\hline AST $>117 \mathrm{IU} / \mathrm{L}$ & 0.643 & $0.229-1.804$ & 0.4012 \\
\hline ALT $>48.5 \mathrm{IU} / \mathrm{L}$ & 1.729 & $0.615-4.860$ & 0.2987 \\
\hline Child-Pugh class $C$ & 0.458 & $0.149-1.414$ & 0.1746 \\
\hline Tumor size $(>6.8$ cm) & 1.438 & $0.86-2.403$ & 0.166 \\
\hline Tumor number (single) & 0.287 & $0.031-2.662$ & 0.2687 \\
\hline Extrahepatic metastasis $(+)$ & 1.153 & $0.369-3.600$ & 0.8064 \\
\hline PVTT (main trunk) & 3.706 & $1.205-11.401$ & 0.0223 \\
\hline AFP $>100 \mathrm{ng} / \mathrm{dL}$ & 0.714 & $0.234-2.177$ & 0.5540 \\
\hline AFP-L3 > $37.4 \%$ & 1.385 & $0.439-4.372$ & 0.5790 \\
\hline $\mathrm{DCP}>100 \mathrm{ng} / \mathrm{dL}$ & 3.485 & $0.381-31.839$ & 0.2687 \\
\hline Variceal rupture (stomach) & 5.286 & $0.516-54.103$ & 0.1606 \\
\hline
\end{tabular}

Other than EVL, treatments for variceal bleeding include medical treatment with vasoactive drugs, balloon tamponade, placement of fully covered self-expanding metallic stents [31], transjugular intrahepatic portosystemic shunts [32], and surgical shunts [33]. Self-expanding metallic stents are not considered effective for the treatment of variceal bleeding due to their high associated incidence of rebleeding [34]. Transjugular intrahepatic portosystemic shunts and surgical shunts are also not indicated in patients with a PVTT and/or poor liver function. Some studies have reported endoscopic treatment of varices in patients with portal HCC invasion. Ng et al. reported data on 14 patients with bleeding esophageal varices and HCC, including 12 who had a PVTT. Successful bleeding control by emergency EIS was achieved for only 6 of 22 bleeding episodes (27\%) [35]. Nakashima et al. reported that in 6 patients with bleeding esophageal varices and HCC portal invasion, the initial variceal hemorrhage was successfully controlled following EIS (100\%). However, 4 of the 6 patients (66.7\%) experienced rebleeding and died of a hemorrhage and liver failure within 1 month [36]. In a study by Ohta et al., acute variceal bleeding was controlled following
Table 4 Independent prognostic factors for overall survival (univariate analysis)

\begin{tabular}{|c|c|c|c|}
\hline Variable & Hazard ratio & $95 \% \mathrm{Cl}$ & $p$ value \\
\hline Age $<62$ years & 0.752 & $0.448-1.263$ & 0.2813 \\
\hline Sex (female) & 0.794 & $0.412-1.529$ & 0.4895 \\
\hline HBV & 0.859 & $0.402-1.836$ & 0.6956 \\
\hline $\mathrm{HCV}$ & 1.509 & $0.727-3.131$ & 0.2698 \\
\hline Ascites (-) & 0.923 & $0.408-1.747$ & 0.8058 \\
\hline Encephalopathy (-) & 0.532 & $0.289-1.135$ & 0.1425 \\
\hline Albumin $<2.9 \mathrm{~g} / \mathrm{dL}$ & 1.084 & $0.651-1.805$ & 0.7565 \\
\hline Total bilirubin $<1.4 \mathrm{mg} / \mathrm{dL}$ & 0.601 & $0.359-1.007$ & 0.0533 \\
\hline Prothrombin time $<68 \%$ & 1.882 & $1.125-3.150$ & 0.0161 \\
\hline Platelet count $<12.0 \times 10^{4} / \mathrm{mm}^{3}$ & 0.692 & $0.413-1.158$ & 0.1618 \\
\hline AST $<117$ IU/L & 0.631 & $0.374-1.063$ & 0.0834 \\
\hline $\mathrm{ALT}<48.5 \mathrm{IU} / \mathrm{L}$ & 0.744 & $0.442-1.253$ & 0.2664 \\
\hline Child-Pugh class A/B & 0.350 & $0.179-0.554$ & $<0.0001$ \\
\hline Tumor size $(<6.8 \mathrm{~cm})$ & 0.696 & $0.416-1.163$ & 0.1540 \\
\hline Tumor number (multiple) & 2.296 & $0.903-5.842$ & 0.0810 \\
\hline Extrahepatic metastasis (-) & 0.800 & $0.455-1.407$ & 0.4385 \\
\hline PVTT (without main trunk) & 1.284 & $0.762-2.162$ & 0.3467 \\
\hline AFP $<100 \mathrm{ng} / \mathrm{dL}$ & 0.619 & $0.352-1.088$ & 0.0958 \\
\hline AFP-L3 $<37.4 \%$ & 0.452 & $0.252-0.813$ & 0.0080 \\
\hline $\mathrm{DCP}<100 \mathrm{ng} / \mathrm{dL}$ & 0.481 & $0.189-1.220$ & 0.1233 \\
\hline Variceal rupture (esophagus) & 1.209 & $0.435-3.344$ & 0.7193 \\
\hline $\operatorname{EVL}(-)$ & 2.031 & $0.279-14.802$ & 0.4844 \\
\hline Rebleeding (-) & 1.091 & $0.651-1.826$ & 0.7415 \\
\hline
\end{tabular}

AFP a-fetoprotein, AFP-L3 lectin-reactive a-fetoprotein, $A L T$ aspartate

aminotransferase, $A S T$ alanine aminotransferase, $C l$ confidence interval, $D C P$ des-gamma carboxyprothrombin, EVL endoscopic variceal band ligation, $H B V$ hepatitis $B$ virus, HCV hepatitis C virus, PVTT portal vein tumor thrombus

emergency EIS in 28 of 29 PVTT patients with bleeding esophageal varices (96.6\%) [37]. Our study showed a hemostasis rate of $98.3 \%$. Thus, based on these earlier reports, EVL was as effective as EIS. Moreover, EVL is now widely available, complications are less common than for EIS [18], and the associated mortality rates are lower than for sclerotherapy $[14,15]$. Our findings confirm that EVL is effective for hemostasis and prevention of immediate death in patients with HCC and a PVTT.

In the present study, we did observe a high rate of rebleeding (39.3\%). A PVTT in the main trunk was

Table 5 Independent prognostic factors for overall survival (multivariate analysis)

\begin{tabular}{lccc}
\hline Variable & Hazard ratio & $95 \% \mathrm{Cl}$ & $p$ value \\
\hline Prothrombin time $<68 \%$ & 1.383 & $0.742-2.575$ & 0.3071 \\
Child-Pugh class A/B & 0.398 & $0.205-0.773$ & 0.0065 \\
AFP-L3 $<37.4 \%$ & 0.464 & $0.251-0.860$ & 0.0147
\end{tabular}

$A F P$ - $L 3$ lectin-reactive a-fetoprotein, $C l$ confidence interval 


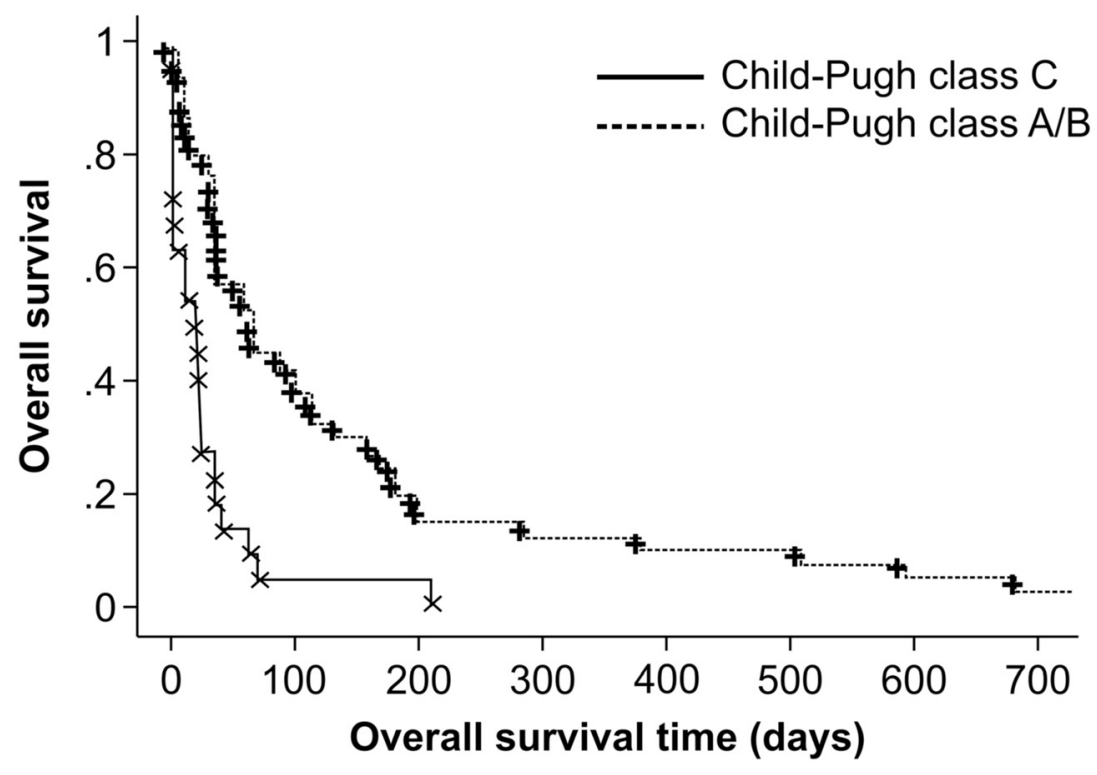

$\begin{array}{lccccc}\text { No.at risk } & 0 \text { day } & 7 \text { days } & 30 \text { days } & 60 \text { days } & 365 \text { days } \\ \text { Child-Pugh C } & 22 & 14 & 6 & 3 & 0 \\ \text { Child-Pugh A/B } & 40 & 38 & 31 & 21 & 5\end{array}$

Fig. 4 Overall survival based on Child-Pugh classification. The solid line connecting the " $x$ " symbols indicates the overall survival of patients classified as Child-Pugh class C, whereas the dotted line connecting the " + " symbols indicates the overall survival of patients classified as Child-Pugh class A/B $(p<.0001)$

predictive for rebleeding. In HCC patients with a PVTT in the main trunk, varices are exacerbated due to the marked elevation of portal vein pressure, leading to rebleeding despite initial hemostasis. The treatment of rebleeding is often difficult in these patients, and secondary prevention of variceal rupture is important for improving the patients' prognoses.

We only studied the emergency treatment of variceal ruptures and therefore cannot discuss the advantages of preventive therapy for varices after initial hemostasis. However, variceal and concurrent HCC treatment might decrease bleeding frequency and improve patient prognosis. For example, Wu et al. reported that sorafenib, an oral multikinase inhibitor, could improve the outcome of variceal bleeding in patients with portal trunk or main branch HCC invasion [38]. In addition, Katamura et al. showed that intra-arterial 5-fluorouracil/interferon- $\alpha$ combined with three-dimensional conformal radiation therapy for a PVTT improved the PVTT response rate and reduced the incidence of portal hypertension-related events [39]. The median survival time of the patients classified as Child-Pugh class A was 133 days in this study, which might be long enough to effectively shrink a PVTT using chemotherapy with sorafenib, 5fluorouracil hepatic arterial infusion with systemic interferon, or radiation to reduce portal vein pressure and the risk of rebleeding. Therefore, we speculate that despite being limited to patients in good general condition having good hepatic function, treatment for PVTT, leading to decreased portal vein pressure, might prevent rebleeding. In this study, one patient survived for more than 5 years. If endoscopic hemostasis is successful and liver cancer is controlled, as in this patient, prolonged survival of similar patients might be achievable.

After initial hemostasis success using EVL, rebleedingfree survival was predicted by the presence of a PVTT in the main trunk influencing portal vein pressure, and overall survival was predicted by Child-Pugh class and AFP-L3 levels, which are not directly related to variceal severity, but rather reflect liver function and the malignant potential of the HCC a determinant of prognosis. Thus, EVL treatment of bleeding varices appears to be sufficiently effective in ensuring that patient survival is no longer affected by bleeding varices but by overall liver function and tumor progression. For better survival of HCC patients with a PVTT concurrent with varices, control of HCC/PVTT and preservation or restoration of liver function are as important as variceal treatment.

Although our study showed that the prognosis of HCC patients with a PVTT and bleeding varices was still poor, preventative therapy for varices might prevent variceal ruptures. Since this study was a retrospective study 
dealing with only emergency hemostasis, the significance of prophylactic variceal treatment in HCC patients with a PVTT could not be assessed. A future prospective study on preventive variceal therapy in these patients is required.

\section{Conclusions}

We evaluated the long- and short-term outcomes of patients with a PVTT who experienced potentially fatal ruptures of their esophageal or gastric varices. We found a rebleeding rate of $39.3 \%$ and a median overall survival time of 36 days. A PVTT in the main portal trunk was predictive of rebleeding, and AFP-L3 levels and ChildPugh class were predictive of overall survival. All EVLtreated patients in this study achieved initial complete hemostasis. Therefore, EVL of variceal ruptures in patients with a PVTT can achieve hemostasis and is useful for preventing immediate death from variceal bleeding. We conclude that EVL is a safe and effective treatment of variceal ruptures in patients with HCC and PVTT. After successful hemostasis, the alleviation of the underlying liver function impairment and tumor control are equally important for a good prognosis.

\section{Ethics statement}

All procedures were in accordance with the ethical standards of the responsible committee on human experimentation (institutional and national) and with the Helsinki Declaration of 1975, as revised in 2008 [5]. This study was approved by the Kyoundo Hospital's ethics committee, and written informed consent was obtained from all patients.

\section{Availability of data and materials}

All the data supporting the study findings are presented in the main manuscript.

\section{Abbreviations}

CT: computed tomography; EIS: endoscopic injection sclerotherapy; EVL: endoscopic variceal band ligation; GOV: gastroesophageal varices; HCC: hepatocellular carcinoma; IGV: isolated gastric varices; PVTT: portal vein tumor thrombus.

\section{Competing interests}

Toshihiro Kawai, Yoko Yashima, Takafumi Sugimoto, Takahisa Sato, Miho Kanda, Nobuyuki Enomoto, Shinpei Sato, and Shuntaro Obi declare no conflicts of interest.

\section{Authors' contributions}

TK collected the clinical data of all patients, participated in the statistical analysis, and drafted the manuscript. SO is the leader of the research team. He conceived the study, contributed to its design and coordination, and helped draft the manuscript. All authors except NE participated in the clinical management of patients with bleeding varices. All authors read and approved the final manuscript.

\section{Acknowledgements}

The authors are grateful to Professor Nobuyuki Enomoto (University of Yamanashi, Yamanashi, Japan) for critically reviewing the manuscript.

\section{Funding}

No funding was received for this study.

Received: 28 October 2015 Accepted: 17 February 2016

Published online: 24 February 2016

References

1. Parkin DM, Bray F, Ferlay J, Pisani P. Global cancer statistics, 2002. CA Cancer J Clin. 2005:55:74-108.

2. D'Amico G, Garcia-Tsao G, Pagliaro L. Natural history and prognostic indicators of survival in cirrhosis: a systematic review of 118 studies. J Hepatol. 2006;44:217-31

3. Llovet JM, Bustmante J, Castells A, Vilana R, Ayuso C, Sala M, et al. Natural history of untreated nonsurgical hepatocellular carcinoma: rationale for the design and evaluation of therapeutic trials. Hepatology. 1999;29:62-7.

4. Stuart KE, Anand AJ, Jenkins RL. Hepatocellular carcinoma in the United States. Prognostic features, treatment outcome, and survival. Cancer. 1996: 77:2217-22.

5. Ikai I, Arii S, Kojiro M, Ichida T, Makuuchi M, Matsuyama Y, et al. Reevaluation of prognostic factors for survival after liver resection in patients with hepatocellular carcinoma in a Japanese nationwide survey. Cancer. 2004; 101:796-802.

6. Fuster J, Garcia-Valdecasas JC, Grande L, Tabet J, Bruix J, Anglada T, et al. Hepatocellular carcinoma and cirrhosis. Results of surgical treatment in a European series. Ann Surg. 1996;223:297-302.

7. Calvet X, Bruix J, Gines P, Bru C, Sole M, Vilana R, et al. Prognostic factors of hepatocellular carcinoma in the west: a multivariate analysis in 206 patients. Hepatology. 1990;12:753-60.

8. Portolani N, Coniglio A, Ghidoni S, Giovanelli M, Benetti A, Tiberio GA, et al. Early and late recurrence after liver resection for hepatocellular carcinoma: prognostic and therapeutic implications. Ann Surg. 2006;243:229-35.

9. Bruix J, Sherman M, American Association for the Study of Liver Diseases. Management of hepatocellular carcinoma: an update. Hepatology. 2011;53: 1020-2.

10. Koike $Y$, Shiratori $Y$, Sato S, Obi S, Teratani T, Imamura M, et al. Des-gammacarboxy prothrombin as a useful predisposing factor for the development of portal venous invasion in patients with hepatocellular carcinoma: a prospective analysis of 227 patients. Cancer. 2001;91:561-9.

11. Minagawa M, Makuuchi M. Treatment of hepatocellular carcinoma accompanied by portal vein tumor thrombus. World J Gastroenterol. 2006; 12:7561-7.

12. D'Amico G, Paglian L, Bosch J. The treatment of portal hypertension: a meta-analytic review. Hepatology. 1995;22:332-54.

13. Van Stiegmann G, Goff JS. Endoscopic esophageal varix ligation: preliminary clinical experience. Gastrointest Endosc. 1988;34:113-7.

14. Lo GH, Lai KH, Cheng JS, Lin CK, Huang JS, Hsu PI, et al. Emergency banding ligation versus sclerotherapy for the control of active bleeding from esophageal varices. Hepatology. 1997:25:1101-4.

15. Stiegmann GV, Goff JS, Michaletz-Onody PA, Korula J, Lieberman D, Saeed ZA, et al. Endoscopic sclerotherapy as compared with endoscopic ligation for bleeding esophageal varices. N Engl J Med. 1992;326:1527-32.

16. Westaby D, Macdougall BR, Williams R. Improved survival following injection sclerotherapy for esophageal varices: final analysis of a controlled trial. Hepatology. 1985;5:827-30.

17. Burroughs AK, Hamilton G, Phillips A, Mezzanotte G, McIntyre N, Hobbs KE. A comparison of sclerotherapy with staple transection of the esophagus for the emergency control of bleeding from esophageal varices. N Engl J Med. 1989;321:857-62.

18. Laine L, El-Newihi HM, Migikovsky B, Sloane R, Garcia F. Endoscopic ligation compared with sclerotherapy for the treatment of bleeding esophageal varices. Ann Intern Med. 1993:119:1-7.

19. Gimson AE, Ramage JK, Panos MZ, Hayllar K, Harrison PM, Williams R, et al. Randomised trial of variceal banding ligation versus injection sclerotherapy for bleeding oesophageal varices. Lancet. 1993:342:391-4.

20. Hashizume M, Ohta M, Ueno K, Tanoue K, Kitano S, Sugimachi K. Endoscopic ligation of esophageal varices compared with injection sclerotherapy: a prospective randomized trial. Gastrointest Endosc. 1993;39:123-6.

21. Hou MC, Lin HC, Kuo Bl, Chen CH, Lee FY, Lee SD. Comparison of endoscopic variceal injection sclerotherapy and ligation for the treatment of esophageal variceal hemorrhage: a prospective randomized trial. Hepatology. 1995;21:1517-22. 
22. Laine L, Cook D. Endoscopic ligation compared with sclerotherapy for treatment of esophageal variceal bleeding. A meta-analysis. Ann Intern Med. 1995;123:280-7.

23. Lo GH, Lai KH, Cheng JS, Hwu JH, Chang CF, Chen SM, et al. A prospective, randomized trial of sclerotherapy versus ligation in the management of bleeding esophageal varices. Hepatology. 1995;22:466-71.

24. Manini MA, Sangiovanni A, Fornari F, Piscaglia F, Biolato M, Fanigliulo L, et al. Study Participants. Clinical and economical impact of 2010 AASLD guidelines for the diagnosis of hepatocellular carcinoma. J Hepatol. 2014;60:995-1001.

25. Garcia-Tsao G, Sanyal AJ, Grace ND, Carey W, Practice Guidelines Committee of the American Association for the Study of Liver Diseases, Practice Parameters Committee of the American College of Gastroenterology. Prevention and management of gastroesophageal varices and variceal hemorrhage in cirrhosis. Hepatology. 2007;46:922-38.

26. Hou MC, Lin HC, Kuo Bl, Lee FY, Schmidt CM, Lee SD. Clinical implications of the white nipple sign and its role in the diagnosis of esophageal variceal hemorrhage. Am J Gastroenterol. 1996;91:2103-9.

27. Terés J, Cecilia A, Bordas JM, Rimola A, Bru C, Rodés J. Esophageal tamponade for bleeding varices. Controlled trial between the Sengstaken-Blakemore tube and the Linton-Nachlas tube. Gastroenterology. 1978;75:566-9.

28. Obi S, Yoshida H, Toune R, Unuma T, Kanda M, Sato S, et al. Combination therapy of intraarterial 5-fluorouracil and systemic interferon-alpha for advanced hepatocellular carcinoma with portal venous invasion. Cancer. 2006:106:1990-7.

29. Augustine S, Muntaner L, Altamirano JT, González A, Saperas E, Dot H, et al. Predicting early mortality after acute variceal hemorrhage based on classification and regression tree analysis. Clin Gastroenterol Hepatol. 2009;7:1347-54.

30. D'Amico G, De Franchis R, Cooperative Study Group. Upper digestive bleeding in cirrhosis. Post-therapeutic outcome and prognostic indicators. Hepatology. 2003;38:599-612

31. Maufa F, Al-Kawas FH. Role of self-expandable metal stents in acute variceal bleeding. Int J Hepatol. 2012;2012:418369.

32. Jalan R, Elton RA, Redhead DN, Finlayson ND, Hayes PC. Analysis of prognostic variables in the prediction of mortality, shunt failure, variceal rebleeding and encephalopathy following the transjugular intrahepatic portosystemic stentshunt for variceal haemorrhage. J Hepatol. 1995:23:123-8.

33. Terés J, Baroni R, Bordas JM, Visa J, Pera C, Rodés J. Randomized trial of portacaval shunt, stapling transection and endoscopic sclerotherapy in uncontrolled variceal bleeding. J Hepatol. 1987;4:159-67.

34. Wright $\mathrm{G}$, Lewis $\mathrm{H}$, Hogan B, Burroughs A, Patch D, O'Beirne J. A selfexpanding metal stent for complicated variceal hemorrhage: experience at a single center. Gastrointest Endosc. 2010;71:71-8.

35. Ng WD, Chan YT, Ho KK, Kong CK. Injection sclerotherapy for bleeding esophageal varices in cirrhotic patients with hepatocellular carcinoma. Gastrointest Endosc. 1989:35:69-70.

36. Nakashima M, Yoshida K, Izuno K, Murata H, Fujiyama S, Sato T. Clinical evaluation of endoscopic injection sclerotherapy for bleeding esophageal varices in liver cirrhosis with hepatocellular carcinoma. Gastroenterol Jpn. 1991;26:36-8.

37. Ohta M, Hashizume M, Tomikawa M, Kamakura T, Akazawa K, Ueno K, et al. Endoscopic injection sclerotherapy for esophageal varices associated with concomitant portal venous thrombus of hepatocellular carcinoma. J Surgical Oncol. 1995:59:125-30.

38. Wu SS, Yen HH, Cheng CY. Oesophageal variceal bleeding in hepatocellular carcinoma with portal vein thrombosis; improved outcome in response to molecular target therapy. Clin Oncol (R Coll Radiol). 2008;20:566-7.

39. Katamura Y, Aikata H, Takaki S, Azakami T, Kawaoka T, Waki K, et al. Intra-arterial 5-fluorouracil/interferon combination therapy for advanced hepatocellular carcinoma with or without three dimensional conformal radiotherapy for portal vein tumor thrombosis. J Gastroenterol. 2009:44:492-502.

\section{Submit your next manuscript to BioMed Central and we will help you at every step:}

- We accept pre-submission inquiries

- Our selector tool helps you to find the most relevant journal

- We provide round the clock customer support

- Convenient online submission

- Thorough peer review

- Inclusion in PubMed and all major indexing services

- Maximum visibility for your research

Submit your manuscript at www.biomedcentral.com/submit
Biomed Central 